\title{
DIFERENÇAS EM CRESCIMENTO E PRODUÇÃO DE GRÃOS ENTRE QUATRO CULTIVARES DE MILHETO PÉROLA ${ }^{1}$
}

\author{
JOSÉ GERALDO², ROBERTO OSCAR PEREYRA ROSSIELLO \\ ADELSON PAULO ARAÚJO ${ }^{4}$ e CARLOS PIMENTEL ${ }^{5}$
}

\begin{abstract}
RESUMO - Foram estudados, mediante análise de crescimento, os padrões de quatro cultivares de milheto pérola (Pennisetum glaucum (L.) R. Brown) e suas relações com a produção de grãos. Em experimento de campo em um Planossolo, foram efetuadas 11 amostragens semanais de biomassa nas cultivares BN-2 e IAPAR (brasileiras, forrageiras), e Guerguera e HKP (africanas, graníferas). As cultivares brasileiras tiveram floração mais precoce e maior biomassa da parte aérea no início do ciclo, e foram superadas pelas africanas após a floração. Não houve diferença significativa entre cultivares na concentração de $\mathrm{N}$ nos tecidos e grãos. As cultivares brasileiras produziram o dobro de panículas e maior perfilhamento. As cultivares africanas tiveram maior produção de grãos que as brasileiras ( 403 contra $268 \mathrm{~g} \mathrm{~m}^{-2}$ ), uma vez que o comprimento de suas panículas e a massa de mil grãos eram cerca de duas vezes superiores em relação às brasileiras. A inferioridade produtiva das cultivares forrageiras foi atribuída, em parte, à baixa densidade de plantio utilizada.
\end{abstract}

Termos para indexação: Pennisetum glaucum, genótipos, área foliar, biomassa, panículas, gramíneas forrageiras, taxa de crescimento, rendimento.

\section{DIFFERENCES ON GROWTH AND GRAIN YIELD BETWEEN FOUR PEARL MILLET CULTIVARS}

\begin{abstract}
The growth patterns of four cultivars of pearl millet (Pennisetum glaucum (L.) R. Brown), and their relationships with grain yield were evaluated through plant growth analysis. In a field experiment in Haplaquult soil, the biomass of cultivars BN-2 and IAPAR (Brazilian cultivars for forage production), Guerguera and HKP (African cultivars for grain yield) was sampled 11 times. Brazilian cultivars presented earlier flowering and higher shoot dry matter in the beginning of the growth cycle, but African cultivars were superior after flowering. There was no significant difference among cultivars for $\mathrm{N}$ concentration of tissues and grains. Brazilian cultivars produced double number of panicles, and a more intense tillering. African cultivars presented higher grain yield than Brazilian cultivars (403 versus $268 \mathrm{~g} \mathrm{~m}^{-2}$ ), due to 1,000-grain weight, and panicle length almost twice greater. The inferior productivity of forage cultivars was in part due to the low planting density used.
\end{abstract}

Index terms: Pennisetum glaucum, genotypes, leaf area, biomass, panicles, feed grasses, growth rate, yields.

${ }^{1}$ Aceito para publicação em 13 de dezembro de 1999.

${ }^{2}$ Eng. Agrôn., M.Sc., Dep. de Solos, Universidade Federal Rural do Rio de Janeiro (UFRRJ), CEP 23890-000 Seropédica, RJ. E-mail: jgeraldo@ufrrj.br

${ }^{3}$ Eng. Agrôn., Dr., Prof. Adjunto, Dep. de Solos, UFRRJ. Bolsista do CNPq. E-mail: ropr@ufrrj.br

${ }^{4}$ Eng. Agrôn., Dr., Prof. Adjunto, Dep. de Solos, UFRRJ. E-mail: aparaujo@ufrrj.br

${ }^{5}$ Eng. Agrôn., Ph.D., Prof. Titular, Dep. de Fitotecnia, UFRRJ. E-mail: pimentel@ufrrj.br

\section{INTRODUÇÃO}

O milheto pérola (Pennisetum glaucum (L.) R. Brown) é uma gramínea anual, cujos grãos constituem importante fonte alimentar em vasta área da África e da Índia, em virtude de sua adaptação à seca e aos solos arenosos com baixo teor de matéria orgânica (Andrews \& Kumar, 1992). Nas regiões semiáridas, onde o milheto é cultivo predominante, o sorgo 
(Sorghum bicolor (L.) Moench) também é amplamente cultivado como cereal, mas sob maiores precipitações e melhores solos (Zaongo et al., 1994).

Enquanto o grão é o principal objetivo do cultivo do milheto na África e Ásia, a forragem e a palhada são importantes produtos secundários para a alimentação animal, combustível e construções (Andrews \& Kumar, 1992). O milheto é usado como cultura forrageira nos Estados Unidos, Austrália, África e Índia, e possui potencial para ser utilizado em rações de aves, suínos e bovinos (Andrews \& Kumar, 1992).

No Brasil, o milheto é usado como pastagem ou forragem (Moraes \& Maraschin, 1988), e também cultivado de forma limitada por produtores de grãos na região do Triângulo Mineiro (Mattos, 1995). Nos Estados de Mato Grosso, Goiás e Mato Grosso do Sul, o milheto é cultivado como cultura de entressafra, para produção de palhada no sistema de plantio direto. Em Mato Grosso, a cultura é utilizada na rotação lavoura-pecuária praticada pelos produtores de soja (Mattos, 1995), e a Embrapa (1997) a recomenda para rotação com a soja no Maranhão. Apesar de adaptado a solos de baixa fertilidade, o milheto é capaz de acumular grandes quantidades de nutrientes: para uma produção de grãos de $3.100 \mathrm{~kg} \mathrm{ha}^{-1}$ no Oeste africano, a cultura removeu 132, 28, 65 e $56 \mathrm{~kg} \mathrm{ha}^{-1}$ de $\mathrm{N}, \mathrm{P}, \mathrm{K}$ e Ca, respectivamente, valores superiores aos observados em milho (Norman et al., 1995).

O milheto apresenta grande amplitude de variabilidade genética no germoplasma já coletado, em que genes de grande importância permanecem não identificados (Andrews \& Kumar, 1992). Nenhuma fonte de germoplasma na espécie deve ser ignorada, em face de uma menor adaptação ou domesticação, pois pode constituir importante fonte de diversidade genética (Bramel-Cox et al., 1986). Cruzamentos de milheto demonstraram que é possível a seleção de linhagens com aumento transgressivo da produção de grãos e da taxa de crescimento (Bramel-Cox et al., 1986).

Apesar de os cultivos de milheto no Brasil voltarem-se principalmente para a produção de palhada, a introdução de genótipos selecionados para produção de grãos poderia propiciar uma renda adicional ao produtor. Para tanto, é necessário caracterizar a adaptação ecofisiológica desses materiais em nossas condições.
Este trabalho objetivou descrever, mediante análise de crescimento, os padrões de quatro genótipos de milheto pérola e suas relações com a produção de grãos.

\section{MATERIAL E MÉTODOS}

O experimento foi conduzido no Campo Experimental da UFRRJ, a $22^{\circ} 45^{\prime} \mathrm{S}, 43^{\circ} 41^{\prime} \mathrm{W}$ e $40 \mathrm{~m}$ de altitude, entre fevereiro e maio de 1996. O delineamento experimental foi em blocos ao acaso, com três repetições. Foram utilizadas quatro cultivares de milheto, a saber: duas, de origem africana, produtoras de grãos (HKP e Guerguera), e duas, brasileiras utilizadas como forrageiras (IAPAR e BN-2). As sementes das cultivares africanas foram obtidas no Centre d'Etude Régional pour l'Amériolation de l'Adaptation à la Sécheresse (CERAAS, Senegal); da cultivar IAPAR, no Instituto Agronômico do Paraná; e da cultivar BN-2 na F\&B Assessoria e Consultoria Agronômica, em Mato Grosso do Sul.

O solo na área do experimento é um Planossolo distrófico (Haplaquult), textura arenosa. Análises químicas (Embrapa, 1979) na camada de 0-20 cm indicaram: $\mathrm{pH}$ em água 5,6; Ca, $11 \mathrm{mmol}_{\mathrm{c}} \mathrm{dm}^{-3} ; \mathrm{Mg}, 5 \mathrm{mmol}_{\mathrm{c}} \mathrm{dm}^{-3} ; \mathrm{Al}$, $0 \mathrm{mmol}_{\mathrm{c}} \mathrm{dm}^{-3}$; K, $0,92 \mathrm{mmol}_{\mathrm{c}} \mathrm{dm}^{-3} ; \mathrm{P}, 4 \mathrm{mg} \mathrm{dm}{ }^{-3}$; C, $18 \mathrm{~g} \mathrm{~kg}^{-1}$. Foi efetuada calagem com $1.000 \mathrm{~kg} \mathrm{ha}^{-1} \mathrm{de}$ calcário, para elevar o teor de $\mathrm{Ca}+\mathrm{Mg}$ para $20 \mathrm{mmol}_{\mathrm{c}} \mathrm{dm}^{-3}$, e foram aplicados nas covas, antes do plantio, $20 \mathrm{~kg} \mathrm{ha}^{-1}$ de N, $26 \mathrm{~kg} \mathrm{ha}^{-1}$ de P e $33 \mathrm{~kg} \mathrm{ha}^{-1}$ de $\mathrm{K}$, respectivamente como uréia, superfosfato simples e cloreto de potássio. Aos 40 dias após o plantio (DAP), foram aplicados $40 \mathrm{~kg} \mathrm{ha}^{-1} \mathrm{de} \mathrm{N}$ em cobertura, na forma de uréia.

As parcelas possuíam seis linhas de $5,5 \mathrm{~m}$ com espaços, entre si, de $1,0 \mathrm{~m}$ e uma cova a cada espaço de $0,5 \mathrm{~m}$, e deixou-se uma planta por cova após o desbaste. O experimento foi conduzido sem irrigação, com precipitação total de $853 \mathrm{~mm}$. As médias ( \pm erro-padrão) da temperatura média e da umidade relativa durante o período experimental foram de $25,3 \pm 0,3^{\circ} \mathrm{C}$ e $65,0 \pm 1,6 \%$, respectivamente.

Foram efetuadas 11 coletas para avaliação da biomassa, em intervalos de sete dias, entre os 30 e 100 DAP; amostrou-se uma planta na segunda e na quinta linha de cada parcela, alternadamente, segundo posições amostrais previamente sorteadas. Em cada coleta, as plantas foram separadas em lâminas foliares, bainhas, colmos e panículas. Nas três primeiras coletas, a área das folhas foi determinada por um medidor eletrônico (LI 3100 Area Meter), e o comprimento e largura máximos, de cada folha, medidos com régua. A regressão do produto dessas variáveis contra a área obtida eletronicamente indicou um coeficiente angular de $0,65(r=0,95)$, usado como fator de correção na 
estimativa da área foliar nas coletas subseqüentes; a análise de variância indicou não haver diferença entre cultivares quanto a este fator. Payne et al. (1991) observaram um fator de 0,68 na estimativa da área foliar em milheto, e este fator foi estável entre coletas. Cada porção vegetal foi secada em estufa a $65^{\circ} \mathrm{C}$, e pesada.

Entre os 25 e 60 DAP, nas duas linhas centrais de cada parcela, foram avaliados o número de perfilhos por planta, número de folhas por perfilho, e altura da planta, correspondente ao colmo de maior elongação. Ao término do experimento, aos $115 \mathrm{DAP}$, foram determinados, em duas plantas das linhas centrais de cada parcela, a produção de grãos, comprimento de panículas, número de panículas e massa de mil grãos. Na coleta aos 79 DAP e nos grãos, cada parte da planta foi moída, determinando-se o teor de $\mathrm{N}$ total pelo método micro-Kjeldahl. Os dados foram convertidos para biomassa por área de terreno e índice de área foliar (IAF), considerando o espaçamento entre plantas.

Para a identificação da homogeneidade das variâncias entre os dados de distintas coletas, foi empregado o teste de Bartlett (programa SAEG 5.0, Universidade Federal de Viçosa), procedendo-se a transformação dos dados em logaritmo natural nos caracteres com variâncias heterocedásticas. Quanto aos caracteres de acumulação de biomassa, a análise de variância avaliou os efeitos de cultivar, coleta (como subparcela) e sua interação. No tocante aos caracteres de acumulação de $\mathrm{N}$ e produção de grãos, a análise de variância avaliou o efeito de cultivar.

Entre as funções de crescimento testadas para ajustes dos dados no tempo (programa SAEG 5.0), foram escolhidos os modelos de Gompertz para massa seca da parte aérea $\left(R^{2}>0,94\right)$, e exponencial polinomial do 3o grau para o IAF $\left(\mathrm{R}^{2}>0,76\right)$. A partir dessas funções, foram derivadas as taxas de crescimento da cultura (TCC) e de assimilação líquida (TAL) (Hunt, 1982). A duração de área foliar, correspondente à integral representada pela área inferior à curva de IAF (Hunt, 1982), foi calculada pelo somatório das médias de dois valores diários consecutivos de IAF, estimados entre os 30 e 100 DAP pelas funções ajustadas.

\section{RESULTADOS E DISCUSSÃO}

\section{Altura da planta e perfilhamento}

As cultivares brasileiras foram mais precoces que as africanas: a IAPAR entrou em floração aos 45 DAP, BN-2 aos 51 DAP, e as cultivares africanas, aos 59 DAP. Além disso, as cultivares brasileiras iniciaram a emissão de perfilhos aos 21 DAP, dois dias antes que as africanas. $\mathrm{O}$ número de perfilhos aumentou até os 45 DAP, tendendo a estabilizar-se após, sem significância da interação entre cultivar e coleta (Tabela 1). Maiti \& Bidinger (1981) observaram que após a floração o número de perfilhos do milheto se estabilizou ou decresceu com a senescência. Foi verificada a seguinte ordem de suporte de perfilhamento: IAPAR $\geq \mathrm{BN}-2>$ Guerguera $\geq \mathrm{HKP}$ (Tabela 1), ou seja, as cultivares forrageiras tiveram perfilhamento mais intenso. O perfilhamento é uma característica importante da cultura, geralmente cultivada em baixas densidades de plantio sob pequena precipitação natural (Norman et al., 1995). O número de perfilhos que atinge a floração depende do genótipo e das condições ambientais, particularmente do espaçamento entre plantas (Maiti \& Bidinger, 1981).

Aos 30 e 45 DAP, a cultivar IAPAR teve plantas de maior altura que BN-2 e Guerguera; já aos 60 DAP não havia diferença significativa entre as cultivares (Tabela 1). Aos 30 e 45 DAP, a cultivar IAPAR teve o

TABELA 1. Altura da planta, número de perfilhos e número de folhas de cultivares de milheto, em quatro épocas de coleta ${ }^{1}$.

\begin{tabular}{|c|c|c|c|c|c|}
\hline \multirow{2}{*}{$\begin{array}{l}\text { Dias após } \\
\text { o plantio }\end{array}$} & \multicolumn{4}{|c|}{ Cultivar } & \multirow[t]{2}{*}{ Média } \\
\hline & $\mathrm{BN}-2$ & IAPAR & HKP & Guerguer & \\
\hline & \multicolumn{5}{|c|}{ Altura da planta $(\mathrm{m})^{2}(\mathrm{CV}, 5,52 \%)$} \\
\hline 25 & $0,05 \mathrm{~b}$ & $0,08 \mathrm{a}$ & $0,08 \mathrm{a}$ & $0,04 \mathrm{~b}$ & $0,06 \mathrm{D}$ \\
\hline 30 & $0,10 \mathrm{ab}$ & $0,13 \mathrm{a}$ & $0,11 \mathrm{ab}$ & $0,07 \mathrm{~b}$ & $0,10 \mathrm{C}$ \\
\hline 45 & $0,63 \mathrm{ab}$ & $0,86 \mathrm{a}$ & $0,43 b c$ & $0,33 \mathrm{c}$ & $0,56 \mathrm{~B}$ \\
\hline \multirow[t]{2}{*}{60} & $1,44 \mathrm{a}$ & $1,76 \mathrm{a}$ & $2,01 \mathrm{a}$ & $1,57 \mathrm{a}$ & $1,70 \mathrm{~A}$ \\
\hline & \multicolumn{5}{|c|}{ Número de perfilhos por planta $(\mathrm{CV}, 15,63 \%)$} \\
\hline 25 & 2,1 & 2,9 & 2,0 & 1,4 & $2,1 \mathrm{C}$ \\
\hline 30 & 5,2 & 6,6 & 4,6 & 3,9 & $5,1 \mathrm{~B}$ \\
\hline 45 & 8,1 & 8,2 & 5,9 & 6,4 & $7,2 \mathrm{~A}$ \\
\hline 60 & 9,1 & 8,2 & 5,9 & 7,9 & $7,8 \mathrm{~A}$ \\
\hline \multirow[t]{2}{*}{ Média } & $6,1 \mathrm{ab}$ & $6,5 \mathrm{a}$ & $4,6 \mathrm{c}$ & $4,9 \mathrm{bc}$ & \\
\hline & \multicolumn{5}{|c|}{ Número de folhas por perfilho ${ }^{2}(\mathrm{CV}, 5,42 \%)$} \\
\hline 30 & $2,5 \mathrm{ab}$ & $2,9 \mathrm{a}$ & $2,3 \mathrm{ab}$ & $2,3 b$ & $2,5 \mathrm{C}$ \\
\hline 45 & $6,9 \mathrm{ab}$ & $8,4 \mathrm{a}$ & $6,6 \mathrm{~b}$ & $6,1 b$ & $7,0 \mathrm{~B}$ \\
\hline 60 & $8,6 \mathrm{~b}$ & $10,1 \mathrm{ab}$ & $11,5 \mathrm{a}$ & $10,1 \mathrm{ab}$ & $10,1 \mathrm{~A}$ \\
\hline
\end{tabular}

${ }^{1}$ Médias seguidas de mesma letra, minúscula na linha e maiúscula na coluna, não diferem pelo teste Tukey a $5 \%$ de probabilidade.

2 Médias dos dados originais, transformados em logaritmo natural antes da análise estatística. 
maior número de folhas por perfilho, e aos 60 DAP, $\mathrm{BN}-2$ teve os menores valores (Tabela 1). Análises de correlação mostraram que a altura da planta, o número de perfilhos, e a área da folha-bandeira contribuem significativamente com a produção de grãos de cultivares de milheto em diferentes ambientes (Maiti \& Soto, 1990).

\section{Produção de biomassa}

A análise de variância dos dados de acumulação de biomassa indicou significância na interação entre cultivar e coleta, evidenciando a existência de diferentes padrões de crescimento entre as cultivares. A cultivar IAPAR acumulou mais massa seca de folha até os $37 \mathrm{DAP}$, enquanto Guerguera teve menor produção de folhas até os $44 \mathrm{DAP}$, ficando as cultivares BN-2 e HKP em posição intermediária (Tabela 2). A partir dos 51 DAP, as cultivares brasileiras foram superadas pelas cultivares africanas, assim permanecendo até o final do ciclo, e os menores valores foram os da cultivar BN-2 (Tabela 2).

Até os 51 DAP, a cultivar IAPAR teve maior produção de massa seca de colmo, mas a partir dos 58 DAP até o final do ciclo, a cultivar HKP foi superior às demais (Tabela 2). Na Tabela 2, há ao menos dois valores considerados anômalos, nas coletas aos 86 e 100 DAP na cultivar Guerguera, que não refletem algum comportamento fisiológico esperado. Isto ilustra algumas dificuldades amostrais, pois visualmente foram observadas diferenças em crescimento entre plantas na mesma parcela, diferenças essas documentadas em estudos anteriores (Pearson, 1984). Além disso, a baixa densidade de plantio deixou poucas posições amostrais disponíveis.

A cultivar IAPAR teve produção de biomassa da parte aérea superior até os $37 \mathrm{DAP}$, enquanto Guerguera teve a menor produção na fase inicial do ciclo (Tabela 2). A partir dos 58 DAP, a cultivar HKP teve o maior acúmulo de massa seca da parte aérea, seguida pela cultivar Guerguera, sendo os valores de BN-2 e IAPAR, em geral, inferiores. Na média das amostragens, as cultivares africanas produziram mais massa seca de folha e de parte aérea que as brasileiras (Tabela 2). Aos 51 DAP, IAPAR e BN-2 alocaram uma maior proporção de matéria seca nos colmos e panículas que HKP e Guerguera, indicando a preco- cidade de desenvolvimento reprodutivo das cultivares forrageiras.

As cultivares brasileiras tiveram estabelecimento mais rápido que as cultivares africanas, evidenciado pela precocidade do perfilhamento e produção de folhas, assim como pela maior acumulação de biomassa no início do ciclo (Tabelas 1 e 2). Essa característica pode ser vantajosa onde exista competição com plantas invasoras ou em locais com suscetibilidade à erosão, especialmente se associada a uma maior densidade de plantio. Por outro lado, as cultivares africanas tiveram maior produção de biomassa no final do ciclo, o que poderá ser útil para produção de palhada em sistemas de rotação de culturas e de plantio direto.

As curvas ajustadas para os dados de massa seca de parte aérea descrevem adequadamente a variação no tempo do crescimento das cultivares (Fig. 1a). Aos 51 DAP as curvas começam a se diferenciar, definindo, a partir dos 65 DAP, as cultivares africanas como grupo de maior produção de biomassa que as seleções nacionais (Fig. 1a). Inicialmente, a TCC foi pequena, e aumentou rapidamente até atingir o máximo por ocasião do florescimento pleno, e diminuindo posteriormente até a maturação (Fig. 1b). Os valores máximos estimados para a TCC foram de 13,15,21 e $19 \mathrm{~g} \mathrm{~m}^{-2} \mathrm{dia}^{-1}$, respectivamente, nas cultivares BN-2, IAPAR, HKP e Guerguera. As cultivares brasileiras atingiram TCC máxima anteriormente às africanas, mas estas últimas apresentaram maiores valores de TCC durante a maior parte do ciclo (Fig. 1b).

\section{Área foliar e taxa de assimilação líquida}

A significância da interação entre cultivar e coleta para o índice de área foliar (IAF) demonstra as variações genotípicas no desenvolvimento ontogenético da área foliar. As cultivares africanas tiveram um período maior de crescimento em área foliar, com IAF máximo de 1,95 aos 60 DAP (Fig. 1c). Já as cultivares BN-2 e IAPAR tiveram menor período de expansão da área foliar, com máximos de IAF estimados em 1,40 e 1,45 aos 54 e 58 DAP, respectivamente (Fig. 1c). Em geral, o máximo IAF no milheto é observado na floração, e posteriormente há um declínio na área foliar com a senescência (Maiti \& Bidinger, 1981). Os valores máximos de IAF de 
milheto em cultivos na Índia foram de 1,7 e 2,9 nas estações seca e úmida, respectivamente, quando a cultura interceptou cerca de $40 \%$ e $60 \%$ da radiação incidente respectivamente (Pearson, 1984); com IAF de 3,5 , a interceptação de radiação foi de $70 \%$ (Craufurd \& Bidinger, 1988).

A área foliar específica decresceu gradativamente, de $29 \mathrm{~m}^{2} \mathrm{~kg}^{-1}$ aos 30 DAP até $8 \mathrm{~m}^{2} \mathrm{~kg}^{-1}$ aos 100 DAP, sem diferenças entre cultivares, demonstrando um processo progressivo de aumento da espessura do limbo foliar com a ontogenia. McIntyre et al. (1993) verificaram uma redução da área foliar específica de milheto após a iniciação da panícula, de 30 para $15 \mathrm{~m}^{2} \mathrm{~kg}^{-1}$.

Pela forma como foi computada a TAL, não é possível efetuar a comparação estatística entre cultivares. Apesar desta restrição, pode-se assumir que a TAL teve um padrão de variação similar entre as cultivares, observando-se um declínio com a ontogenia, mais acentuado após 79 DAP (Fig. 1d), o que concorda com observações em outras espécies cultivadas (Hunt, 1982). Os valores estimados aos 30 a 40 DAP são próximos aos registrados em espécies $\mathrm{C}_{4}$ em fase de rápido crescimento, da ordem de

TABELA 2. Massa seca de folha, colmo e parte aérea, e índice de área foliar, de cultivares de milheto, em 11 épocas de coleta ${ }^{1}$.

\begin{tabular}{|c|c|c|c|c|c|c|c|c|}
\hline \multirow{2}{*}{$\begin{array}{c}\text { Dias após o } \\
\text { plantio }\end{array}$} & \multicolumn{4}{|c|}{ Cultivar } & \multicolumn{4}{|c|}{ Cultivar } \\
\hline & $\mathrm{BN}-2$ & IAPAR & HKP & Guerguera & $\mathrm{BN}-2$ & IAPAR & HKP & Guerguera \\
\hline & \multicolumn{4}{|c|}{ Massa seca de folha $\left(\mathrm{g} \mathrm{m}^{-2}\right)(\mathrm{CV}, 6,58 \%)$} & \multicolumn{4}{|c|}{ Massa seca de colmo $\left(\mathrm{g} \mathrm{m}^{-2}\right)(\mathrm{CV}, 5,10 \%)$} \\
\hline 30 & $4,7 \mathrm{~b}$ & $6,5 \mathrm{a}$ & $4,8 b$ & $2,3 \mathrm{c}$ & $0,3 b$ & $0,5 \mathrm{a}$ & $0,2 \mathrm{~d}$ & $0,2 \mathrm{c}$ \\
\hline 37 & $21,2 b$ & $30,1 \mathrm{a}$ & $22,6 b$ & $15,3 \mathrm{c}$ & $2,8 b$ & $4,3 \mathrm{a}$ & $2,1 \mathrm{c}$ & $1,8 \mathrm{c}$ \\
\hline 44 & $43,5 b$ & $58,0 \mathrm{a}$ & $61,6 \mathrm{a}$ & $38,2 \mathrm{c}$ & $14,3 \mathrm{c}$ & $21,9 \mathrm{a}$ & $17,8 \mathrm{~b}$ & $6,3 \mathrm{~d}$ \\
\hline 51 & $42,5 \mathrm{c}$ & $51,8 \mathrm{~b}$ & $77,3 \mathrm{a}$ & $42,3 \mathrm{a}$ & $63,3 \mathrm{a}$ & $63,2 \mathrm{a}$ & $46,3 b$ & $9,2 \mathrm{c}$ \\
\hline 58 & $52,6 \mathrm{~d}$ & $60,2 c$ & $83,8 b$ & $100,8 \mathrm{a}$ & $103,7 b$ & $103,9 b$ & $162,7 \mathrm{a}$ & $166,1 \mathrm{a}$ \\
\hline 65 & $63,6 \mathrm{c}$ & $70,0 \mathrm{~b}$ & $102,8 \mathrm{a}$ & $111,6 a$ & $152,1 \mathrm{~b}$ & $155,2 \mathrm{~b}$ & $209,9 a$ & $205,4 a$ \\
\hline 72 & $57,3 \mathrm{~d}$ & $64,1 \mathrm{c}$ & $86,9 \mathrm{~b}$ & $101,7 \mathrm{a}$ & $133,3 d$ & $159,2 \mathrm{c}$ & $253,4 \mathrm{a}$ & $217,0 \mathrm{~b}$ \\
\hline 79 & $53,0 \mathrm{~d}$ & $58,1 \mathrm{c}$ & $88,1 \mathrm{~b}$ & $99,5 b$ & $132,5 b$ & $151,3 b$ & $241,0 \mathrm{a}$ & $229,3 a$ \\
\hline 86 & $61,0 \mathrm{~d}$ & $72,0 \mathrm{c}$ & $115,1 \mathrm{a}$ & $82,8 b$ & $157,3 \mathrm{c}$ & $190,5 b$ & $297,3 \mathrm{a}$ & $135,1 d$ \\
\hline 93 & $74,4 \mathrm{~b}$ & $95,4 \mathrm{a}$ & $94,5 \mathrm{a}$ & $99,7 \mathrm{a}$ & $199,5 b$ & $238,6 a$ & $253,4 \mathrm{a}$ & $205,2 b$ \\
\hline 100 & $76,4 \mathrm{bc}$ & $73,0 \mathrm{c}$ & $79,7 b$ & $127,7 \mathrm{a}$ & $181,4 \mathrm{c}$ & $245,9 b$ & $266,4 a b$ & $300,3 a$ \\
\hline \multirow[t]{2}{*}{ Média } & $41,6 \mathrm{c}$ & $49,7 b$ & $58,9 \mathrm{a}$ & $51,5 \mathrm{ab}$ & $44,3 \mathrm{ab}$ & $54,3 \mathrm{a}$ & $54,1 \mathrm{a}$ & $39,5 b$ \\
\hline & \multicolumn{4}{|c|}{ Massa seca da parte aérea $\left(\mathrm{g} \mathrm{m}^{-2}\right)(\mathrm{CV}, 4,99 \%)$} & \multicolumn{4}{|c|}{ Índice de área foliar $\left(\mathrm{m}^{2} \mathrm{~m}^{-2}\right)(\mathrm{CV}, 5,70 \%)$} \\
\hline 30 & $7,1 \mathrm{~b}$ & $9,7 \mathrm{a}$ & $6,9 b$ & $3,5 \mathrm{c}$ & $0,14 \mathrm{a}$ & $0,20 \mathrm{a}$ & $0,13 \mathrm{a}$ & $0,06 b$ \\
\hline 37 & $36,5 b$ & $53,4 a$ & $36,7 b$ & $24,1 \mathrm{c}$ & $0,59 a b$ & $0,78 \mathrm{a}$ & $0,60 a b$ & $0,45 b$ \\
\hline 44 & $84,2 \mathrm{~b}$ & $107,3 \mathrm{a}$ & $116,4 \mathrm{a}$ & $63,9 c$ & $1,15 \mathrm{a}$ & $1,30 \mathrm{a}$ & $1,34 \mathrm{a}$ & $0,93 \mathrm{a}$ \\
\hline 51 & $162,7 \mathrm{a}$ & $162,1 \mathrm{a}$ & $168,0 \mathrm{a}$ & $75,3 b$ & $0,97 \mathrm{a}$ & $1,15 \mathrm{a}$ & $1,65 \mathrm{a}$ & $1,02 \mathrm{a}$ \\
\hline 58 & $250,6 \mathrm{c}$ & $282,3 b$ & $414,4 a$ & $384,1 \mathrm{a}$ & $1,24 b$ & $1,23 b$ & $1,60 \mathrm{ab}$ & $2,19 \mathrm{a}$ \\
\hline 65 & $361,4 b$ & $385,3 b$ & $485,4 a$ & $501,7 \mathrm{a}$ & $1,40 \mathrm{a}$ & $1,26 \mathrm{a}$ & $1,85 \mathrm{a}$ & $2,03 \mathrm{a}$ \\
\hline 72 & $332,9 d$ & $479,6 \mathrm{c}$ & $637,2 \mathrm{a}$ & $570,2 \mathrm{~b}$ & $1,07 \mathrm{a}$ & $1,17 \mathrm{a}$ & $1,40 \mathrm{a}$ & $1,61 \mathrm{a}$ \\
\hline 79 & $431,4 d$ & $483,0 \mathrm{c}$ & $744,0 \mathrm{a}$ & $664,5 b$ & $0,96 \mathrm{a}$ & $0,87 \mathrm{a}$ & $1,23 \mathrm{a}$ & $1,41 \mathrm{a}$ \\
\hline 86 & $510,3 \mathrm{c}$ & $573,1 \mathrm{~b}$ & $948,6 \mathrm{a}$ & $599,4 \mathrm{~b}$ & $0,77 \mathrm{a}$ & $0,71 \mathrm{a}$ & $1,25 \mathrm{a}$ & $1,11 \mathrm{a}$ \\
\hline 93 & $667,8 \mathrm{c}$ & $735,8 b$ & $843,9 a$ & $678,6 b c$ & $0,65 b$ & $1,01 \mathrm{ab}$ & $1,12 \mathrm{ab}$ & $1,22 \mathrm{a}$ \\
\hline 100 & $627,0 \mathrm{~d}$ & $712,7 \mathrm{c}$ & $860,9 b$ & $1000,2 \mathrm{a}$ & $0,69 a b$ & $0,58 b$ & $0,52 b$ & $1,06 \mathrm{a}$ \\
\hline Média & $322,8 b$ & $370,6 a b$ & $477,2 \mathrm{a}$ & $373,9 \mathrm{a}$ & $0,88 b$ & $0,93 \mathrm{ab}$ & $1,16 a b$ & $1,19 \mathrm{a}$ \\
\hline
\end{tabular}

${ }^{1}$ Médias dos dados originais, transformados em logaritmo natural antes da análise estatística; médias seguidas da mesma letra na linha não diferem pelo teste Tukey a $5 \%$ de probabilidade. 
$12 \mathrm{~g} \mathrm{~m}^{-2} \mathrm{dia}^{-1}$ (Beadle, 1993). De forma geral, HKP apresentou maiores valores de TAL durante o ciclo da cultura (Fig. 1d).

As diferenças genotípicas observadas na TCC foram associadas principalmente ao IAF, uma vez que a TAL foi similar para as quatro cultivares (Fig. 1). Após a floração, os declínios na TCC estiveram mais estreitamente associados às tendências de variação no IAF do que na TAL. Pearson (1984) su- gere que as perspectivas para aumento da produção do milheto através do conhecimento da fisiologia do desenvolvimento e dos componentes da produção são mais promissoras que a seleção visando a taxas fotossintéticas. A duração da área foliar é considerada de maior importância na determinação do rendimento final de uma cultura do que o próprio IAF (Hunt, 1982). As cultivares Guerguera e HKP tiveram maior duração de área foliar que BN-2 e IAPAR (Ta-
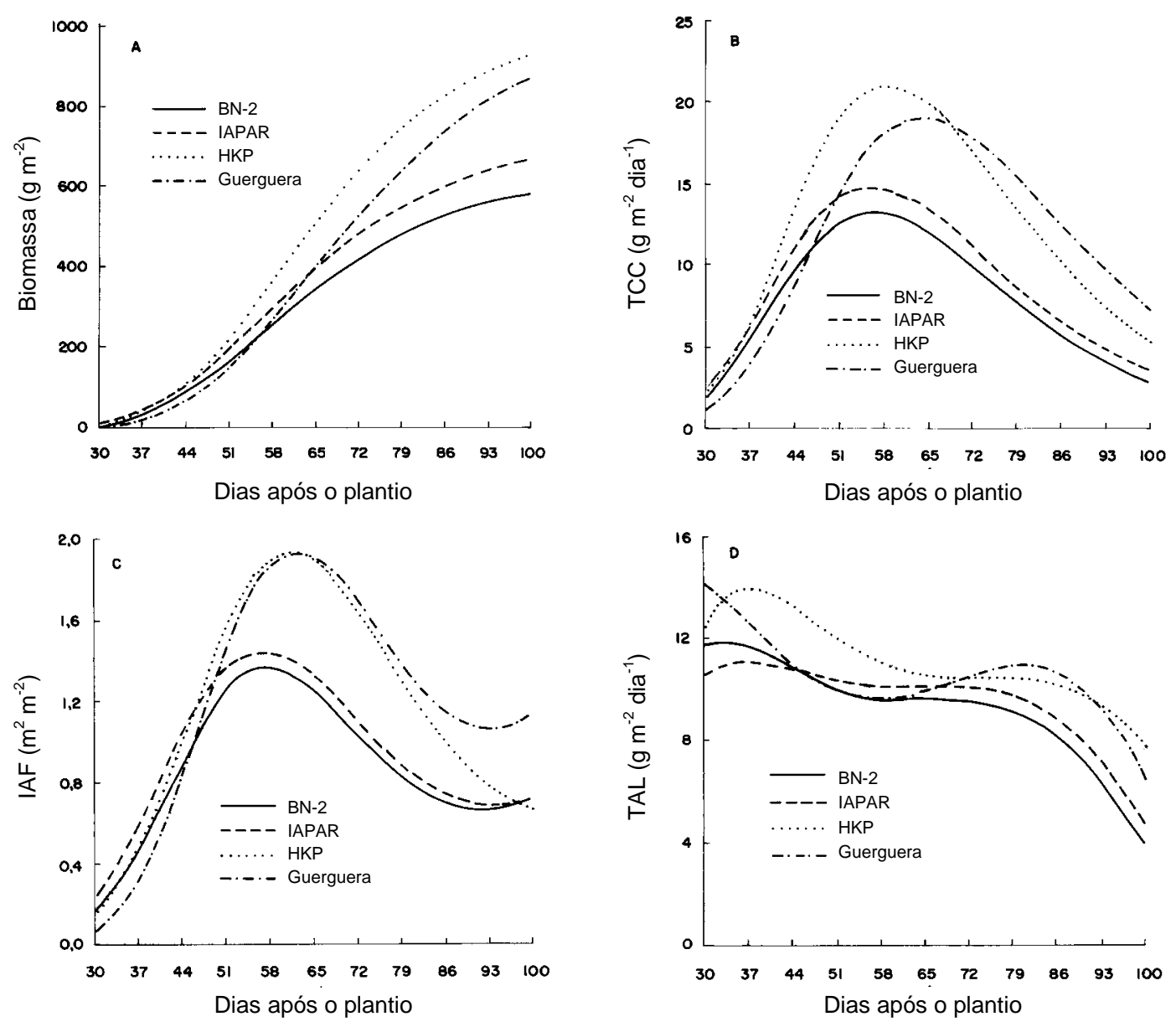

FIG. 1. Curvas ajustadas aos dados primários, e taxas de crescimento derivadas, de cultivares de milheto. A: massa seca da parte aérea, estimada pelo modelo de Gompertz; B: taxa de crescimento da cultura (TCC); C: índice de área foliar (IAF), estimado pelo modelo exponencial polinomial do $3^{\circ}$ grau; D: taxa de assimilação líquida (TAL). 
bela 4), o que pode explicar, na ausência de diferenças muito marcantes na TAL, a superioridade produtiva das cultivares africanas.

\section{Teor e conteúdo de nitrogênio}

Os teores de $\mathrm{N}$ nas folhas aos 79 DAP estiveram na faixa de 15 a $18 \mathrm{mg} \mathrm{g}^{-1}$ (Tabela 3 ), sem diferenças significativas entre cultivares. Da mesma forma, não houve diferenças entre cultivares nos teores de $\mathrm{N}$ em colmos e bainhas. Por outro lado, na cultivar IAPAR o teor de $\mathrm{N}$ nas panículas foi superior às demais (Tabela 3 ). Esses valores estão muito próximos aos registrados em milheto aos 70 dias após emergência, sob adequada umidade no solo (Payne et al., 1995) e sob adubação com $45 \mathrm{~kg} \mathrm{ha}^{-1}$ de N (Mohammed \& Clegg, 1993).

As diferenças entre cultivares no conteúdo de $\mathrm{N}$ por área de terreno são explicadas pelas diferenças na produção de biomassa. Guerguera e HKP tiveram um acúmulo maior de $\mathrm{N}$ em folhas e colmos do que BN-2 e IAPAR aos 79 DAP (Tabela 3), como reflexo de seu maior crescimento nesse estádio. Zaongo et al. (1994) verificaram conteúdos de $\mathrm{N}$ na parte aérea de milheto, variando entre 1,8 e $6,3 \mathrm{~g} \mathrm{~m}^{-2}$.

\section{Produção de grãos}

As cultivares Guerguera e HKP tiveram rendimento de grãos de, respectivamente, 407 e $400 \mathrm{~g} \mathrm{~m}^{-2}$, significativamente superiores aos rendimentos de $\mathrm{BN}-2$ $\left(275 \mathrm{~g} \mathrm{~m}^{-2}\right)$ e IAPAR $\left(260 \mathrm{~g} \mathrm{~m}^{-2}\right)$ (Tabela 4). Desta forma, as cultivares brasileiras produziram, em média, $34 \%$ menos grãos que as africanas. Os rendimentos obtidos podem ser considerados elevados, em virtude dos relativamente baixos valores de IAF e TCC observados (Fig. 1). Em 11 experimentos na Índia, Kumar et al. (1983) registraram variações no rendimento entre 44 e $451 \mathrm{~g} \mathrm{~m}^{-2}$, enquanto Dancette (1983) verificou, em seis experimentos, no Senegal, varia-

TABELA 3. Teor e conteúdo de nitrogênio na folha, colmo, bainha e panícula de cultivares de milheto, avaliados aos 79 dias após plantio ${ }^{1}$.

\begin{tabular}{|c|c|c|c|c|c|c|c|c|c|}
\hline \multirow[t]{2}{*}{ Cultivar } & \multicolumn{4}{|c|}{ Teor de nitrogênio $\left(\mathrm{mg} \mathrm{g}^{-1}\right)$} & \multicolumn{5}{|c|}{ Conteúdo de nitrogênio $\left(\mathrm{g} \mathrm{m}^{-2}\right)$} \\
\hline & Folha & Colmo & Bainha & Panícula & Folha & Colmo & Bainha & Panícula & P. aérea \\
\hline $\mathrm{BN}-2$ & 17,72 & 3,16 & 8,71 & $12,79 \mathrm{~b}$ & $0,97 b$ & $0,43 b$ & 0,29 & 2,71 & 4,40 \\
\hline IAPAR & 15,84 & 3,37 & 6,72 & $15,07 \mathrm{a}$ & $0,92 b$ & $0,50 \mathrm{~b}$ & 0,34 & 3,53 & 5,22 \\
\hline HKP & 15,41 & 4,07 & 5,20 & $12,34 b$ & $1,39 \mathrm{ab}$ & $0,95 \mathrm{a}$ & 0,27 & 4,42 & 7,09 \\
\hline Guerguera & 15,67 & 2,82 & 4,79 & $12,82 b$ & $1,58 \mathrm{a}$ & $0,62 \mathrm{ab}$ & 0,33 & 3,47 & 6,00 \\
\hline $\mathrm{CV}(\%)$ & 12,09 & 28,41 & 44,22 & 5,98 & 19,49 & 24,17 & 46,75 & 24,67 & 21,87 \\
\hline
\end{tabular}

${ }^{1}$ Médias seguidas da mesma letra, ou desprovidas de letra, não diferem pelo teste Tukey a $5 \%$ de probabilidade.

TABELA 4. Produção de grãos e componentes da produção de cultivares de milheto ${ }^{1}$.

\begin{tabular}{|c|c|c|c|c|c|}
\hline \multirow[t]{2}{*}{ Caráter } & \multicolumn{4}{|c|}{ Cultivar } & \multirow{2}{*}{$\begin{array}{l}\text { CV } \\
(\%)\end{array}$} \\
\hline & $\mathrm{BN}-2$ & IAPAR & HKP & Guerguera & \\
\hline Duração de área foliar (dia) & 61,9 & 67,6 & 83,6 & 85,7 & \\
\hline Produção de grãos $\left(\mathrm{g} \mathrm{m}^{-2}\right)$ & $275 b$ & $260 b$ & $400 \mathrm{a}$ & $407 a$ & 19,72 \\
\hline Comprimento de panícula (m) & $0,22 \mathrm{c}$ & $0,29 \mathrm{c}$ & $0,60 \mathrm{a}$ & $0,46 b$ & 11,59 \\
\hline Número de panículas por planta & $9,8 \mathrm{a}$ & $7,3 \mathrm{~b}$ & $3,2 \mathrm{c}$ & $4,9 \mathrm{c}$ & 19,35 \\
\hline Massa de mil grãos (g) & $6,8 b$ & $6,8 b$ & $12,0 \mathrm{a}$ & $12,1 \mathrm{a}$ & 9,18 \\
\hline Teor de $\mathrm{N}$ no grão $\left(\mathrm{mg} \mathrm{g}^{-1}\right)$ & $14,8 \mathrm{a}$ & $16,2 \mathrm{a}$ & $12,9 \mathrm{a}$ & $12,0 \mathrm{a}$ & 17,70 \\
\hline Conteúdo de $\mathrm{N}$ no grão $\left(\mathrm{g} \mathrm{m}^{-2}\right)$ & $3,74 a$ & $4,00 \mathrm{a}$ & $5,22 \mathrm{a}$ & $4,60 \mathrm{a}$ & 27,04 \\
\hline
\end{tabular}

${ }^{1}$ Médias seguidas da mesma letra na linha não diferem pelo teste Tukey a $5 \%$ de probabilidade; a duração de área foliar não sofreu análise de variância 
ções entre 156 e $279 \mathrm{~g} \mathrm{~m}^{-2}$; no México, Maiti \& Soto (1990) registraram rendimentos em quatro experimentos entre 42 e $238 \mathrm{~g} \mathrm{~m}^{-2}$. Entretanto, o potencial produtivo da espécie é mais elevado, com rendimentos de até $713 \mathrm{~g} \mathrm{~m}^{-2}$ sob adubação com $90 \mathrm{~kg} \mathrm{ha}^{-1}$ de N nos Estados Unidos (Mohammed \& Clegg, 1993).

Os elevados rendimentos obtidos podem ser atribuídos à boa disponibilidade hídrica no cultivo (853 mm), associada a temperaturas adequadas (média de $25,3^{\circ} \mathrm{C}$ ), dentro da faixa ótima de $25^{\circ} \mathrm{C}$ a $27^{\circ} \mathrm{C}$ para a máxima taxa de crescimento do milheto (Squire et al., 1984). Além disso, a adubação com $60 \mathrm{~kg} \mathrm{ha}^{-1}$ de $\mathrm{N}$ efetuada pode ser considerada adequada para obtenção de bons rendimentos (Mohammed \& Clegg, 1993).

A produção de grãos foi positivamente correlacionada com a massa de mil grãos e com o comprimento das panículas $(r=0,75, \mathrm{p}<0,001)$, e negativamente correlacionada com o número de panículas $(r=-0,65, p<0,01)$. Sendo assim, os componentes de produção de maior expressão no rendimento foram a massa de mil grãos e o comprimento de panícula, indicativo do número de grãos por panícula. As cultivares africanas apresentaram massa de mil grãos e comprimento de panículas aproximadamente duas vezes superiores às cultivares brasileiras; já as cultivares brasileiras tiveram em média número de panículas por planta duas vezes maior (Tabela 4). A cultivar Guerguera teve panículas com comprimento menor que HKP, mas em compensação produziu mais panículas (Tabela 4).

O número de grãos e o tamanho do grão contribuíram de forma equivalente para a variação na produção de 50 genótipos de milheto na Índia (Norman et al., 1995). Craufurd \& Bidinger (1988) sugerem que em milheto a seleção visando ao aumento do número de panículas não deve resultar em aumento significativo no potencial produtivo, pela relação inversa com o tamanho da panícula, e que o aumento na produção deve vir através do aumento do número de grãos. Estimativas de herdabilidade com base em plantas individuais de milheto para caracteres como comprimento da panícula, altura da planta, massa de sementes e produção de grãos indicam que a seleção massal pode ser eficiente (Rattunde et al., 1989).

Não houve diferença significativa entre cultivares no teor de $\mathrm{N}$ no grão (Tabela 4). A correlação entre produção de grãos e teor de N no grão foi negativa, mas não-significativa, observando-se que as cultivares africanas, de maior rendimento, tiveram menor teor de N no grão (Tabela 4). Kumar et al. (1983) também observaram correlação negativa mas nãosignificativa entre produção de grãos e teor de proteína nos grãos de milheto, sugerindo, assim, que pode ser possível a seleção com vistas ao aumento do teor de proteína no grão, sem efeitos depressivos no rendimento. $\mathrm{O}$ acúmulo de $\mathrm{N}$ no grão foi determinado principalmente pelas diferenças no rendimento, e portanto os genótipos HKP e Guerguera tiveram um conteúdo de $\mathrm{N}$ no grão superior ao dos genótipos BN-2 e IAPAR, sem, contudo, atingir diferença significativa (Tabela 4). Com o aumento da produção de grãos de milheto, em geral o teor de proteína no grão diminui, apesar de o acúmulo de proteína por hectare aumentar (Andrews \& Kumar, 1992).

De forma geral, as cultivares africanas apresentaram maior potencial produtivo, tanto de matéria seca quanto de grãos, que as cultivares brasileiras forrageiras. Entretanto, esses resultados são parcialmente condicionados pela densidade de plantio utilizada (20.000 plantas ha-1), recomendada para facilitar os tratos culturais em cultivos para produção de grãos (25.000 plantas ha-1, segundo Béninga (1993), mas inferior à utilizada em vários estudos,

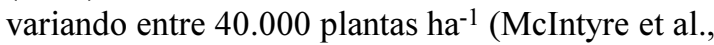
1993; Zaongo et al., 1994) e 130.000 plantas ha-1 (Kumar et al., 1983; Bramel-Cox et al., 1986). Uma maior densidade de plantio poderia aumentar a produção de biomassa e de área foliar das cultivares forrageiras, diminuindo as diferenças de potencial produtivo entre os grupos africano e brasileiro. A maior densidade de plantio resulta em maior produção de biomassa por área de terreno, apesar de a produção de matéria seca por cova ser maior sob menor densidade (Bationo et al., 1990).

Apesar dessa restrição, os resultados obtidos permitem concluir que a introdução de genótipos similares às cultivares africanas aqui avaliadas pode aumentar o rendimento de grãos, sem prejuízo da produção de matéria seca.

São necessários estudos complementares sobre o comportamento desses materiais sob diferentes densidades de plantio. A área foliar apresenta-se como um carácter preferencial em programas de seleção de cultivares com vistas à produção de biomassa. 


\section{CONCLUSÕES}

1. As cultivares brasileiras BN-2 e IAPAR são mais precoces que as cultivares africanas Guerguera e HKP.

2. As cultivares africanas têm maior produção de biomassa, maior taxa de crescimento da cultura e maior índice de área foliar que as cultivares brasileiras.

3. As cultivares africanas produzem mais grãos que as cultivares brasileiras, em virtude das maiores massa de mil grãos e comprimento da panícula.

\section{REFERÊNCIAS}

ANDREWS, D.J.; KUMAR, K.A. Pearl millet for food, feed, and forage. Advances in Agronomy, San Diego, v.48, p.89-139, 1992.

BATIONO, A.; CHRISTIANSON, C.B.; BAETHGEN, W.E. Plant density and nitrogen fertilizer effects on pearl millet production in Niger. Agronomy Journal, Madison, v.82, p.290-295, 1990.

BEADLE, C.L. Growth analysis. In: HALL, D.O.; SCURLOCK, J.M.O.; BOLHÀRNORDENKAMPF, H.R.; LEEGOOD, R.C.; LONG, S.P. (Ed.). Photosynthesis and production in a changing environment: a field and laboratory manual. London : Chapman \& Hall, 1993. p.36-46.

BÉNINGA, M.B. Bilan des travaux d'amélioration variétale en Côte D'Ivoire. In: HAMON, S. (Ed.). Le mil en Afrique : diversité génétique et agrophysiologique: potentialités et contraintes pour l'amélioration génétique et l'agriculture. Paris : ORSTOM, 1993. p.21-32.

BRAMEL-COX, P.J.; ANDREWS, D.J.; FREY, K.J. Exotic germplasm for improving grain yield and growth rate in pearl millet. Crop Science, Madison, v.26, p.687-690, 1986.

CRAUFURD, P.Q.; BIDINGER, F.R. Effect of the duration of the vegetative phase on shoot growth, development and yield in pearl millet (Pennisetum americanum (L.) Leeke). Journal of Experimental Botany, Oxford, v.39, p.124-139, 1988.

DANCETTE, C. Besoins en eau du mil au Sénégal: adaptation en zone semi-aride tropicale. Agronomie Tropicale, Montpellier, v.38, p.267-280, 1983.
EMBRAPA. Centro Nacional de Pesquisa de Soja (Londrina, PR). Recomendações técnicas para a cultura da soja na região Central do Brasil 1997/98. Londrina, 1997. 171p. (Embrapa-CNPSo. Documentos, 106).

EMBRAPA. Serviço Nacional de Levantamento e Conservação de Solos (Rio de Janeiro, RJ). Manual de métodos de análise de solo. Rio de Janeiro, 1979. não paginado.

HUNT, R. Plant growth curves: the functional approach to plant growth analysis. London : E. Arnold, 1982. 248 p.

KUMAR, K.A.; GUPTA, S.C.; ANDREWS, D.J. Relationship between nutritional quality characters and grain yield in pearl millet. Crop Science, Madison, v.23, p.232-235, 1983.

MCINTYRE, B.D.; FLOWER, D.J.; RIHA, S.J. Temperature and soil water status effects on radiation use and growth of pearl millet in a semi-arid environment. Agricultural and Forest Meteorology, Amsterdam, v.66, p.221-227, 1993.

MAITI, R.K.; BIDINGER, F.R. Growth and development of the pearl millet plant. Patancheru : International Crops Research Institute for the Semi-Arid Tropics, 1981. 14p. (ICRISAT. Research Bulletin, 6).

MAITI, R.K.; SOTO, G.G.L. Effect of four sowing date environments on growth, development and yield potentials of 15 pearl millet cultivars (Pennisetum americanum L. Leeke) during autumn-winter seasons in Marin, N.L., Mexico. Journal of Experimental Botany, Oxford, v.41, p.1609-1618, 1990.

MATTOS, J.L.S. de. Comportamento de Pennisetum americanum (L.) Leeke, Sorghum sudanense (Piper) Stapf e Euchlaena mexicana Schrad. sob diferentes regimes hídricos e doses de nitrogênio. Lavras : UFLA, 1995. 96p. Dissertação de Mestrado.

MOHAMMED, M.S.; CLEGG, M.D. Pearl milletsoybean rotation and nitrogen fertilizer effects on millet productivity. Agronomy Journal, Madison, v.85, p.1009-1013, 1993.

MORAES, A.; MARASCHIN, G.E. Pressões de pastejo e produção animal em milheto cv. Comum. Pesquisa Agropecuária Brasileira, Brasília, v.23, n.2, p.197-205, fev. 1988 
NORMAN, M.J.T.; PEARSON, C.J.; SEARLE, P.G.E. The ecology of tropical food crops. 2.ed. Cambridge : University Press, 1995. 430p.

PAYNE, W.A.; HOSSNER, L.R.; ONKEN, A.B.; WENDT, C.W. Nitrogen and phosphorus uptake in pearl millet and its relation to nutrient and transpiration efficiency. Agronomy Journal, Madison, v.87, p.425-431, 1995.

PAYNE, W.A.; WENDT, C.W.; HOSSNER, L.R.; GATES, C.E. Estimating pearl millet leaf area and specific leaf area. Agronomy Journal, Madison, v.83, p.937941, 1991.

PEARSON, C. Pennisetum millet. In: GOLDSWORTHY, P.R.; FISHER, N.M. (Ed.). The physiology of tro- pical field crops. New York : J. Wiley, 1984. p.281304.

RATTUNDE, H.F.; SINGH, P.; WITCOMBE, J.R. Feasibility of mass selection in pearl millet. Crop Science, Madison, v.29, p.1423-1427, 1989.

SQUIRE, G.R.; MARSHALL, B.; TERRY, A.C.; MONTEITH, J.L. Response to temperature in a stand of pearl millet. VI. Light interception and dry matter production. Journal of Experimental Botany, Oxford, v.35, p.599-610, 1984.

ZAONGO, C.G.L.; HOSSNER, L.R.; WENDT, C.W. Root distribution, water use, and nutrient uptake of millet and grain sorghum on West African soils. Soil Science, Baltimore, v.157, p.379-388, 1994. 